\title{
Using Manufacturing Simulations to Evaluate Metacognitive Awareness in Industrial Engineering Students
}

\section{Dr. Faisal Aqlan, Penn State Erie, The Behrend College}

Dr. Faisal Aqlan is an assistant professor of industrial engineering at Penn State Behrend. He earned his $\mathrm{Ph} . \mathrm{D}$. in Industrial and Systems Engineering from the State University of New York at Binghamton in 2013. Dr. Aqlan is a senior member of the Institute of Industrial and Systems Engineers (IISE) and has received numerous awards and honors including the IBM Vice President award for innovation excellence.

Dr. Heather C. Lum, Penn State Erie, The Behrend College

Dr. Lisa Jo Elliott, Penn State Erie, The Behrend College

Dr. Richard Zhao, Penn State Erie, The Behrend College

Dr. Richard Zhao is an Assistant Professor of Computer Science and Software Engineering at the Behrend College of the Pennsylvania State University. He received his B.S. degree in Computer Science from the University of Toronto, and his M.S. and Ph.D. degrees in Computing Science from the University of Alberta in 2009 and 2015, respectively. His research focuses on the application of artificial intelligence in games and machine learning techniques in data mining. 


\title{
Using Manufacturing Simulations to Evaluate Metacognitive Awareness in Industrial Engineering Students
}

\begin{abstract}
Metacognition is the process of "thinking about thinking" such that individuals learn methods to understand the way that they learn, what they are lacking in their current learning strategies, and how to improve. Metacognition is an important dimension of problem solving because it allows problem solvers to analyze problems and find viable solutions. In design and manufacturing, problem solving focuses on optimizing the product design and improving the production process. In this paper, we discuss the development of physical simulation games to evaluate metacognitive awareness in industrial engineering students. In order to develop metacognitive awareness, students participate in group manufacturing simulations and each group evaluate the work of other groups. Metacognitive awareness inventory (MAI) is used to evaluate the metacognitive awareness of the students before and after their participation in the simulation activities. MAI is an instrument designed to assess general self-regulated learning skills. The instrument has 52 items that are classified by type of cognitive knowledge: declarative (DK), procedural (PK), and conditional (CK); or by specific metacognitive process: planning (P), information management strategies (IMS), monitoring (M), debugging strategies (DS), and evaluation (E). Results show that the students improved their metacognitive awareness for all the MAI categories. However, only the improvement in the last three categories (i.e., M, DS, and E) was statistically significant.
\end{abstract}

\section{Background}

Engineers working in design and manufacturing fields often confront challenges not because of a lack of technical ability, but rather due to a lack of professional skills. One such important skill is metacognitive understanding of their own and their team's problem-solving abilities. Metacognition is the process of "thinking about thinking" such that individuals learn methods to understand the way that they learn, what they are lacking in their current learning strategies, and how to improve. Metacognition includes monitoring and control activities and it is a pre-requisite to any problem solving because it affects critical thinking, creativity, and innovation [1]. In 
addition, metacognition provides a key to understand learning differences and difficulties experienced by individuals. Metacognition allows for effective use of problem solver's skills and knowledge, and provides greater adaptability to diverse tasks and ultimately leads to effective problem solving.

In order to examine metacognitive thinking for problem solvers, several techniques can be utilized, including: (1) verbally sharing thoughts and using those thoughts as objects for thinking [2], (2) teamwork and social setting in which learners hear and see problem solving approaches of peers and compare to their own strategies, to determine accurate and efficient methods [3], and sociocultural setting in which problem solvers interact and participate in highquality thinking that promotes metacognitive thinking [4]. Previous studies indicate that these types of activities elicit measurable problem-solving activities and are indicative of metacognitive understanding during individual and group performance during problem solving tasks.

Metacognitive thoughts can be separated into two categories, knowledge of cognition and regulation of cognition [1]. The first category, knowledge of cognition, includes declarative, procedural, and conditional knowledge. Declarative knowledge is the knowledge about what you know; procedural is the knowledge about how to do a procedure; and conditional knowledge is knowledge about when and why to do a particular procedure. The second category, regulation of cognition, focuses on the monitoring of the thought process and includes planning, managing information, monitoring progress, debugging when things go wrong, and evaluating one's over effectiveness and efficiency of one's thinking [2]. Figure 1 shows the different categories of metacognition.

Students who know how to regulate their thinking can effectively use what they know to improve their problem-solving performance [5]. In design and manufacturing, metacognition can help students improve their skills and utilize their knowledge to solve problems effectively. Moreover, metacognition allows students to use their knowledge in situations where they can develop a greater ability to adapt to diverse tasks and ultimately acquire better learning [3]. Students do not obtain this knowledge automatically and must instead develop their 
metacognitive knowledge through direct and explicit instruction. This will allow students to access and understand their own thinking and work on improving and utilizing it [2].

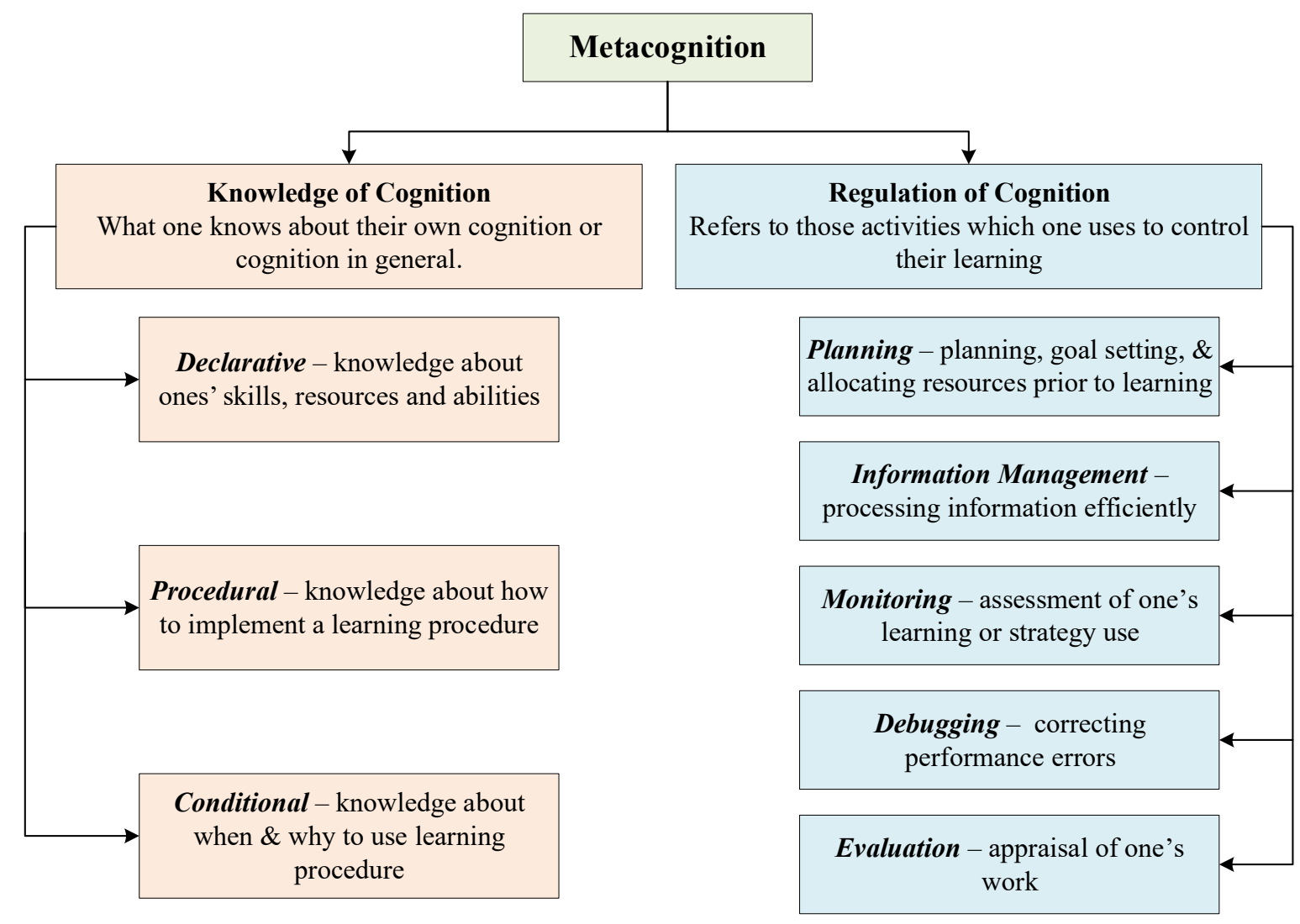

Figure 1. Taxonomy of Metacognition [1]

Several studies have discussed the metacognitive awareness among students and how to measure it. Studies stated "metacognitive thinking includes a judgment of meaning which is necessary for learning and problem solving" [6]. Metacognition allows the person to be aware of what information is known and what information is needed and to control her application of the relevant information in problem solving. This has been studied extensively studies on metacognition and problem solving [7]. Studies indicated that problem solving skills benefit from improving metacognition [8]. Moreover, there are many studies demonstrating the correlation between improved metacognition and improved problem solving [6]. For example, one study used forty participants who were students attending medical school [6,9]. Participants took Heppner's problem-solving inventory. Then, the experimental group, learned problem solving 
skills through a metacognitive approach for ten 2-hour sessions. In the control group, a conventional problem-solving teaching approach was used for same amount of time. There was a significant difference between the groups in terms of their scores on Heppner's inventory and their problem-solving skills as observed. The authors concluded that metacognitive instruction positively influenced learning outcomes [9].

In this paper, we integrate metacognitive skill development with manufacturing simulations and study the impact of students' participation in hands-on problem-solving activities in design and manufacturing on developing their metacognitive awareness skills.

\section{Research Design}

The proposed research is based on conducting manufacturing simulations and having students work in groups to assemble Lego cars while evaluating their metacognitive awareness skills. Simulation games can effectively be used to teach manufacturing systems concepts and improve students' metacognitive awareness. In this research, we developed manufacturing simulations to teach students the common concepts used with manufacturing system and assess their metacognitive skills (see Figure 2). The concepts include manufacturing system inputs and outputs, manufacturing processes, manufacturing layouts, and performance measures.
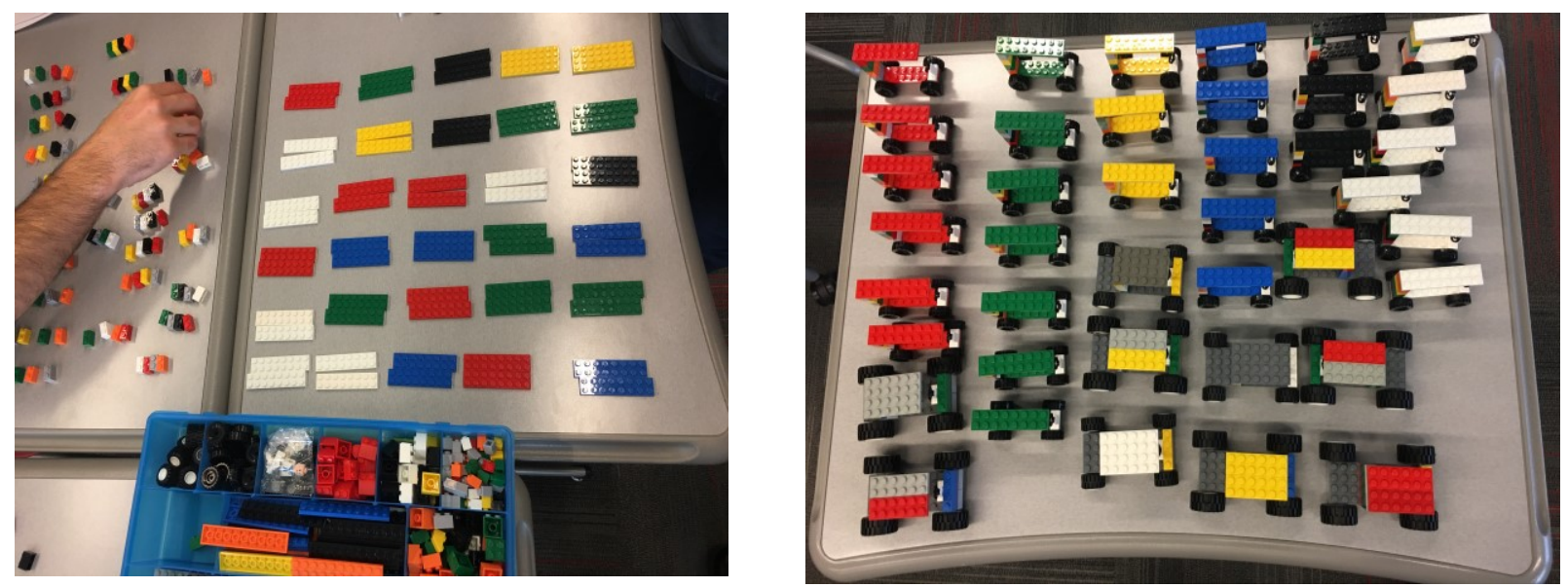

Figure 2. Sample pictures of the simulation games

The manufacturing simulation games were conducted in an undergraduate engineering course, which focuses on teaching manufacturing systems to industrial engineering students. 
Students worked in groups to perform the assembly of a Lego car according to customer requirements. Below are some pictures for the simulation games. The class consists of 23 students, 18 males and 5 females.

\section{Results and Analysis}

To evaluate the metacognitive awareness, we used the Metacognitive Awareness Inventory (MAI). MAI was developed by Schraw and Dennison [1] and it consists of 52 questions that measure the metacognition awareness in terms of: Knowledge about cognition (declarative knowledge (DK), procedural knowledge (PK), and conditional knowledge (DK)) and regulation of cognition (planning (P), information management strategies (IMS), comprehension monitoring (M), debugging strategies (DS), and evaluation (E)).

Students participated in manufacturing simulations and their metacognitive awareness was measured using MAI before and after conducting the simulations. Students worked on the simulation activities in groups and each group was asked to grade the work of the other groups. The MAI survey was performed by individual students. Table 1 shows the results for the metacognitive assessment as a difference between the scores for "Before" and "After" and it is noted that all the scores were higher. Figure 3 shows the MAI scores for all the students grouped by the MAI category (i.e., DK, PK, CK, P, IMS, M, DS, and E).

Table 1. Comparing MAI scores

\begin{tabular}{|l|l|l|l|l|l|l|l|l|}
\hline & \multicolumn{3}{|l|}{ Cognitive Knowledge } & \multicolumn{4}{|c|}{ Metacognitive Process (regulation of cognition) } \\
\cline { 2 - 9 } & DK & PK & CK & P & IMS & M & DS & E \\
\hline Mean change & 0.054 & 0.016 & 0.016 & 0.052 & 0.017 & 0.186 & 0.193 & 0.138 \\
\hline Standard Error & 0.047 & 0.034 & 0.024 & 0.038 & 0.045 & 0.040 & 0.054 & 0.034 \\
\hline
\end{tabular}

Figures 4 and 5 show the scores for males and females, respectively. It is noted that when the data was separated by gender, the general pattern for the scores did not show a change. In their study, Misu and Masi [10] found that there is no significant difference between students' metacognition awareness of men and women; and this is consistent with our findings. 


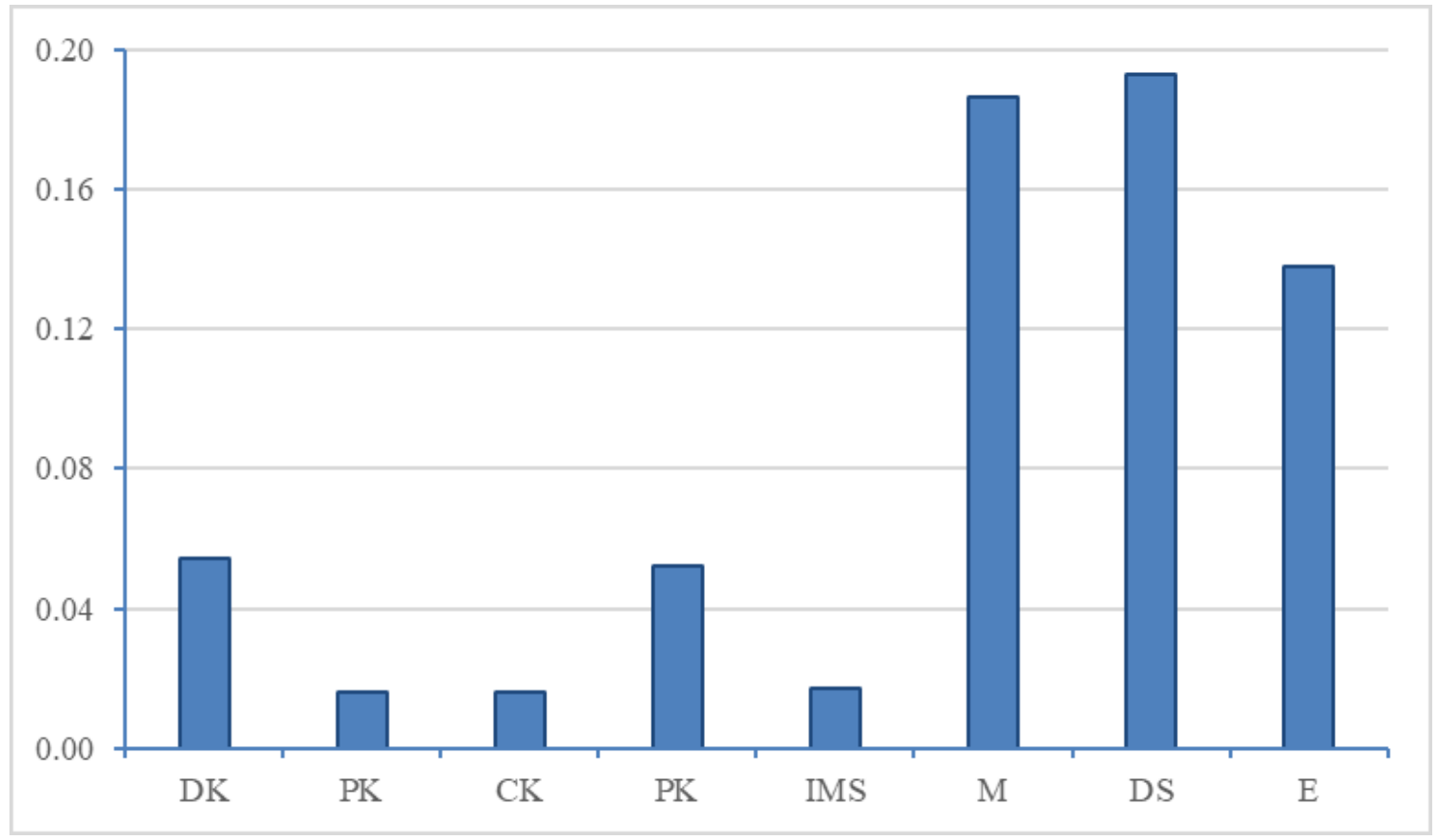

Figure 3. MAI difference scores for the students overall

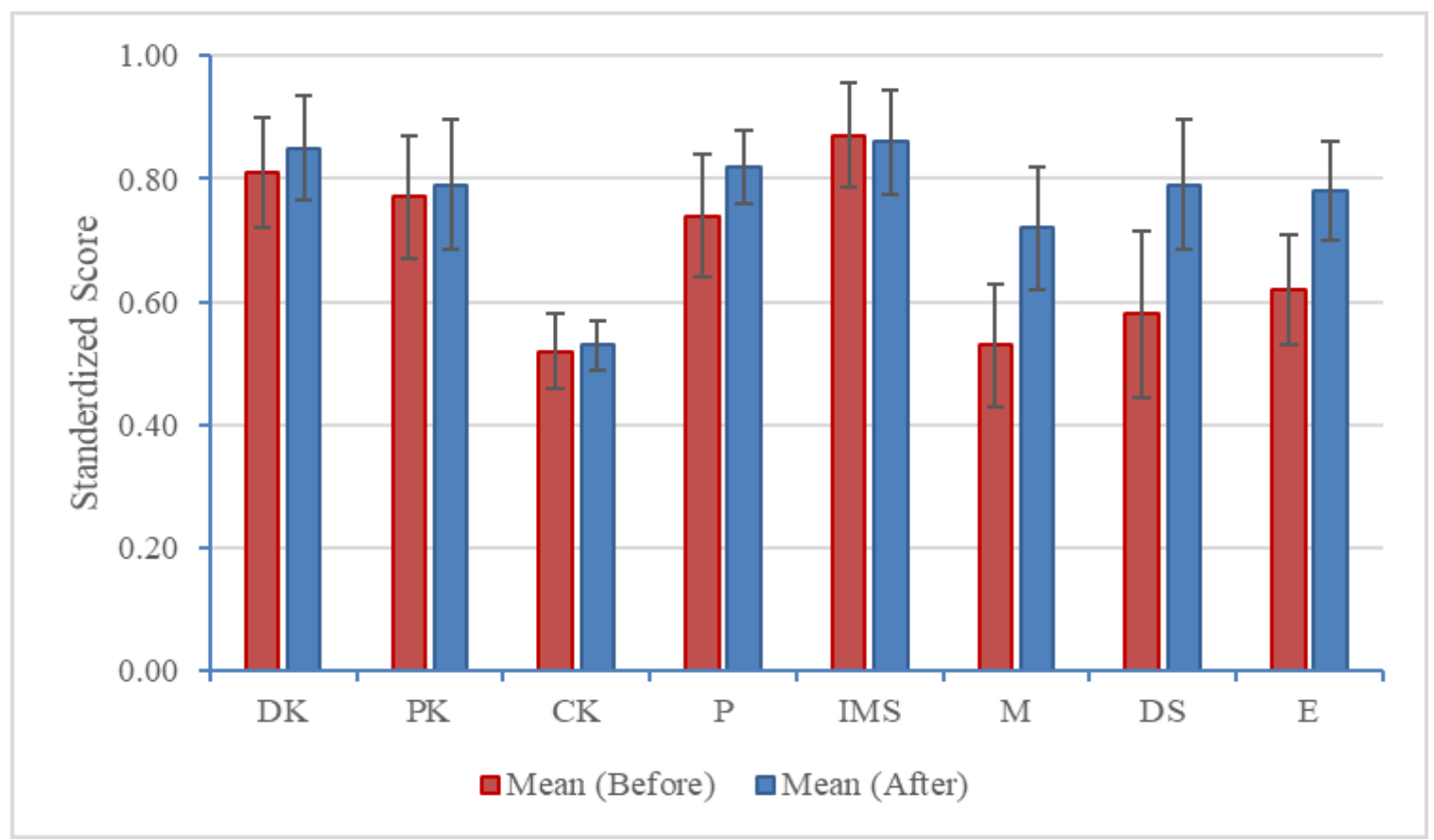

Figure 4. MAI scores for the male students 


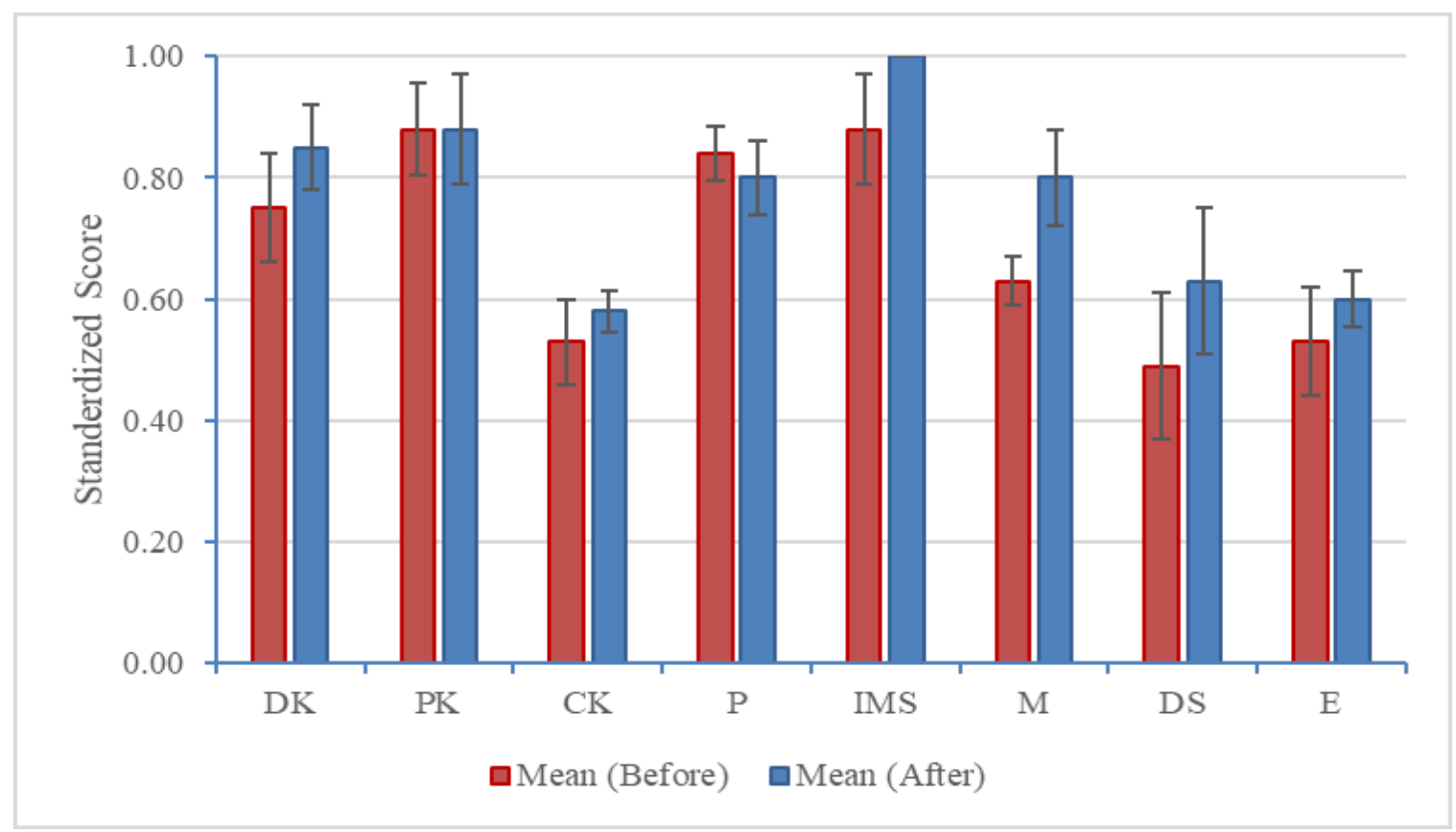

Figure 5. MAI scores for the female students

Additionally, an ANOVA analysis of the difference between the scores was run. We found that $F(7,154)=3.559, p=.001$ with an effect size of $\eta^{2}=0.139$. Table 2 shows the contrasts between items using the Least Significant Difference contrasts (LSD). It can be noted that there were not significant differences between measures DK and any of the other measures in this sample. We found a Cronbach's Alpha of 0.72 within this sample, which indicate that the internal consistency of the test is acceptable.

Table 2. Least Significant Difference, Significant contrasts

\begin{tabular}{|l|l|l|l|l|l|l|l|l|}
\hline & DK & PK & CK & P & IMS & M & DS & E \\
\hline DK & $\mathrm{ns}$ & $\mathrm{ns}$ & $\mathrm{ns}$ & $\mathrm{ns}$ & $\mathrm{ns}$ & $\mathrm{ns}$ & $\mathrm{ns}$ & $\mathrm{ns}$ \\
\hline PK & $\mathrm{ns}$ & $\mathrm{ns}$ & $\mathrm{ns}$ & $\mathrm{ns}$ & $\mathrm{ns}$ & $\begin{array}{l}-0.170, \mathrm{p} \\
=.006\end{array}$ & $\begin{array}{l}-0.176, \mathrm{p} \\
=.019\end{array}$ & $\begin{array}{l}-0.121, \mathrm{p} \\
=.024\end{array}$ \\
\hline $\mathrm{CK}$ & $\mathrm{ns}$ & $\mathrm{ns}$ & $\mathrm{ns}$ & $\mathrm{ns}$ & $\mathrm{ns}$ & $\begin{array}{l}-0.170, \mathrm{p} \\
=.0001\end{array}$ & $\begin{array}{l}-0.176, \\
\mathrm{p}=.008\end{array}$ & $\begin{array}{l}-0.121, \mathrm{p} \\
=.003\end{array}$ \\
\hline $\mathrm{P}$ & $\mathrm{ns}$ & $\mathrm{ns}$ & $\mathrm{ns}$ & $\mathrm{ns}$ & $\mathrm{ns}$ & $\begin{array}{l}-0.134, \mathrm{p} \\
=.011\end{array}$ & $\begin{array}{l}-0.140, \mathrm{p} \\
=.034\end{array}$ & $\mathrm{~ns}$ \\
\hline IMS & $\mathrm{ns}$ & $\mathrm{ns}$ & $\mathrm{ns}$ & $\mathrm{ns}$ & $\mathrm{ns}$ & $\begin{array}{l}-0.169, \mathrm{p} \\
=.013\end{array}$ & $\begin{array}{l}-0.175, \mathrm{p} \\
=.021\end{array}$ & $\mathrm{~ns}$ \\
\hline $\mathrm{M}$ & $\mathrm{ns}$ & $\begin{array}{l}0.170, \mathrm{p} \\
=.006\end{array}$ & $\begin{array}{l}0.170, \mathrm{p} \\
=.0001\end{array}$ & $\begin{array}{l}0.134, \mathrm{p} \\
=.011\end{array}$ & $\begin{array}{l}0.169, \mathrm{p} \\
=.013\end{array}$ & $\mathrm{~ns}$ & $\mathrm{~ns}$ & $\mathrm{~ns}$ \\
\hline $\mathrm{DS}$ & $\mathrm{ns}$ & $\begin{array}{l}0.176, \mathrm{p} \\
=.019\end{array}$ & $\begin{array}{l}0.176, \mathrm{p} \\
=.008\end{array}$ & $\begin{array}{l}0.140, \mathrm{p} \\
=.034\end{array}$ & $\begin{array}{l}0.175, \mathrm{p} \\
=.021\end{array}$ & $\mathrm{~ns}$ & $\mathrm{~ns}$ & $\mathrm{~ns}$ \\
\hline $\mathrm{E}$ & $\mathrm{ns}$ & $\begin{array}{l}0.121, \mathrm{p} \\
=.024\end{array}$ & $\begin{array}{l}0.121, \mathrm{p} \\
=.003\end{array}$ & $\mathrm{~ns}$ & $\mathrm{~ns}$ & $\mathrm{~ns}$ & $\mathrm{~ns}$ & $\mathrm{~ns}$ \\
\hline
\end{tabular}




\section{Conclusions and Future Work}

This paper discussed the assessment of metacognitive awareness in industrial engineering students. Students participated in group manufacturing simulations and each group evaluate the work of other groups. Metacognitive awareness inventory (MAI) was used to evaluate the metacognitive awareness of the students before and after their participation in the simulation activities. MAI is an instrument designed to assess general self-regulated learning skills. It was found that students improved their metacognitive awareness, in general, after participating the simulation activities. It was also found that there were not significant differences between measures DK and any of the other measures in this sample. We found a Cronbach's Alpha of 0.72 within this sample.

Future work will focus on conducting the simulation and the metacognitive assessment in larger student groups from different engineering disciplines. Moreover, both physical and virtual reality simulations of manufacturing systems will be developed and students will be evaluated in both environments.

\section{Acknowledgement}

This research is funded by the National Science Foundation NSF RIEF \# 1830741: Advanced Modeling of Metacognitive Problem Solving and Group Effectiveness in Collaborative Engineering Teams. Any opinions, findings, or conclusions found in this paper are those of the authors and do not necessarily reflect the views of the sponsor.

\section{References}

[1] Schraw, G., and Dennison, R. S., (1994) 'Assessing metacognitive awareness', Contemporary Educational Psychology, 19(4), 460-475.

[2] Conrady, K., (2015) 'Modeling metacognition: Making thing visible in a content course for teachers', REDIMAT, 4(2), 132- 160. 
[3] Pintrich, P. R., (2002) 'The role of metacognitive knowledge in learning, teaching, and assessment', Theory into Practice, 41(4), 219-225.

[4] Martinez, M. E. (2006). 'What is metacognition?' Phi Delta Kappan, 696-699.

[5] Schoenfeld, A., (2007) 'What is mathematical proficiency and how can it be assessed?, In A. Schoenfeld (Ed.), Assessing Mathematical Proficiency, 53, 59-73. Cambridge: Cambridge University Press.

[6] Safari, Y. and Meskini, H., (2016) 'The effect of metacognitive instruction on problem solving skills in Iranian students of Health Sciences', Global journal of health science, 8, 150.

[7] Tobias, S., and Everson, H. T., (2002) 'Knowing what you know and what you don't: Further research on metacognitive knowledge monitoring', Research Report No. 2002-3. College Entrance Examination Board.

[8] Sengul, S., and Katranci, Y., (2015) 'Meta-cognitive aspects of solving indefinite integral problems', Procedia-Social and Behavioral Sciences, 197, 622-629.

[9] Heppner, P., (1988) 'The problem solving inventory', Consulting Psychologists Press Palo Alto, CA.

[10] Misu, L., and Masi, L., (2017) 'Comparison of metacognition awareness of male and female students based on mathematics ability in department of mathematics education of Halu Oleo University', International Journal of Education and Research, 5(6), 43-50. 